\title{
The influence of the treatment response on the impact of resection margin status after preoperative chemoradiotherapy in locally advanced rectal cancer
}

Joo Ho Lee ${ }^{1}$, Eui Kyu Chie ${ }^{1,5^{*}}$, Kyubo Kim¹, Seung-Yong Jeong², Kyu Joo Park², Jae-Gahb Park², Gyeong Hoon Kang ${ }^{3}$, Sae-Won Han ${ }^{4}$, Do-Youn Oh${ }^{4}$, Seock-Ah Im ${ }^{4}$, Tae-You Kim ${ }^{4}$, Yung-Jue Bang ${ }^{4}$ and Sung W Ha, ${ }^{1,5}$

\begin{abstract}
Background: Circumferential resection margin (CRM) and distal resection margin (DRM) have different impact on clinical outcomes after preoperative chemoradiotherapy (CRT) followed by surgery. Effect and adequate length of resection margin as well as impact of treatment response after preoperative CRT was evaluated.

Methods: Total of 403 patients with rectal cancer underwent preoperative CRT followed by total mesorectal excision between January 2004 and December 2010. After applying the criterion of margin less than $0.5 \mathrm{~cm}$ for CRM or less than $1 \mathrm{~cm}$ for DRM, 151 cases with locally advanced rectal cancer were included as a study cohort. All patients underwent conventionally fractionated radiation with radiation dose over 50 Gy and concurrent chemotherapy with 5-fluorouracil or capecitabine. Postoperative chemotherapy was administered to 142 patients (94.0\%). Median follow-up duration was 43.1 months.

Results: The 5-year overall survival (OS), disease-free survival (DFS), distant metastasis-free survival (DMFS) rates, and locoregional control rates (LRC) were $84.5 \%, 72.8 \%, 74.2 \%$, and $86.3 \%$, respectively. CRM of $1.5 \mathrm{~mm}$ and DRM of $7 \mathrm{~mm}$ were cutting points showing maximal difference in a maximally selected rank method. In univariate analysis, CRM of $1.5 \mathrm{~mm}$ was significantly related with worse clinical outcomes, whereas DRM of $7 \mathrm{~mm}$ was not. In multivariate analysis, CRM of $1.5 \mathrm{~mm}$, and ypN were prognosticators for all studied endpoints. However, CRM was not a significant prognostic factor for good responders, defined as patients with near total regression or T down-staging, which was found in $16.5 \%$ and $40.5 \%$ among studied patients, respectively. In contrast, poor responders demonstrated a significant difference according to the CRM status for all studied end-points.
\end{abstract}

Conclusions: Close CRM, defined as $1.5 \mathrm{~mm}$, was a significant prognosticator, but the impact was only prominent for poor responders in subgroup analysis. Postoperative treatment strategy may be individualized based on this finding. However, findings from this study need to be validated with larger cohort.

Keywords: Rectal cancer, Preoperative chemoradiotherapy, Resection margin, Treatment response

\footnotetext{
* Correspondence: ekchie93@snu.ac.kr

'Department of Radiation Oncology, Seoul National University College of

Medicine, Seoul, Korea

5 Institute of Radiation Medicine, Medical Research Center, Seoul National

University, Seoul, Korea

Full list of author information is available at the end of the article
} 


\section{Background}

Resection margin (RM) of rectal cancer is a well-known and strong prognostic factor for survival as well as recurrence $[1,2]$. However, recent strategies of preoperative treatment comprised of various modalities influence the significance of RM. Among them, long-course chemoradiotherapy (CRT) has different features compared to other approaches. Polish study reported that long-course CRT significantly reduced RM involvement and increased pathological complete remission rate over short-course radiation alone [3]. Thus, significance and adequate length of RM after long-course CRT should be re-evaluated in patients receiving long-course preoperative CRT.

In addition, several studies evaluated the relation with other factors and treatment approaches for patients with positive circumferential resection margin (CRM) [4,5] whereas many previous studies suggested only the prognostic effects of CRM [1,6-10]. In above mentioned studies, it was found that additional postoperative radiotherapy could not compensate the negative impact of positive CRM [4,5]. To investigate the biology of CRM and the relation with treatment approach, present study hypothesized that significance of positive RM could be determined by tumor biology of residual tumor cells. Tumor biology or responsiveness to anti-cancer therapy could be represented as degree of treatment response after preoperative CRT. Results from EORTC 22921 have shown that patients downstaged by preoperative CRT are more likely to benefit from adjuvant chemotherapy [18]. As tumor regression is one of the distinct features of long-course CRT over short-course radiotherapy or up-front surgery [3], in the setting of long-course preoperative CRT, impact of RM needs to be evaluated in relation to treatment response.

Present study was carried out to evaluate the effect and adequate length of RM in patients who underwent conventionally fractionated preoperative CRT for rectal cancer. In addition, effect of treatment response after preoperative CRT was assessed in relation to RM status.

\section{Methods}

\section{Patients}

After the approval of the institutional ethical review board of Seoul National University Hospital, medical records of 403 patients with rectal cancer who underwent preoperative CRT followed by total mesorectal excision between January 2004 and December 2010 were retrospectively reviewed. Inclusion criteria were: (1) histologically confirmed primary rectal cancer, (2) cT3-4 or N + without clinical evidence of distant metastasis, (3) total mesorectal excision following preoperative CRT, (4) close RM less than $0.5 \mathrm{~cm}$ for CRM or less than $1.0 \mathrm{~cm}$ for distal resection margin (DRM). There were 151 cases meeting the inclusion criteria.
Patient characteristics are shown in Table 1. In all patients, the clinical workup included digital rectal examination, complete blood count, liver function test, carcinoembryonic antigen (CEA) level, colonoscope, computed tomography $(\mathrm{CT})$ of the chest and abdomino-pelvis. Magnetic resonance imaging (MRI) of the pelvis and whole body positron-emission tomography (PET) were performed in 149 patients $(98.6 \%)$ and 30 patients (19.9\%), respectively. Pathologic confirmation of primary lesion was done prior to preoperative CRT for all patients.

\section{Treatment}

Following the diagnosis of rectal cancer, all 151 patients underwent preoperative concurrent CRT for rectal cancer. The reasons for preoperative treatment were as follows: locally advanced tumor invasion (cT3-4) in 137 patients, clinically positive lymph node with cT2 in 14 patients.

All patients underwent CT simulation in prone treatment position. The gross tumor volume (GTV), consisting of all detectable tumors and suspicious lymph node, was determined from the endoscopy, CT, MRI, and PET finding. Initial clinical target volume (CTV) covered GTV and mesorectal tissues with craniocaudal extension and regional lymphatics including the perirectal, presacral, and the both internal iliac nodes. The initial planning target volume for large field (PTV-LF) included the initial CTV plus a $1 \mathrm{~cm}$ margin. Reduced CTV included primary lesion harboring mesorectal tissues with craniocaudal extension and grossly enlarged lateral pelvic lymph node. The secondary PTV for reduced field (PTV-RF) was also expanded for $1 \mathrm{~cm}$ from the reduced CTV. The initial radiotherapy for PTV-LF consisted of 25 fractions of 1.8 Gy (median: 45 Gy). The supplemental boost to PTV-RF consisted of 3-6 fractions of 1.8 Gy (range: 5.4-10.8 Gy), so total dose was 50.4-55.8 Gy (median: 50.4 Gy). Boost dose beyond 5.4Gy was offered to patients with initial cT4 presentation or limited mobility on physical examination midway through pre-operative treatment. All patients underwent concurrent chemotherapy with radiation, consisting of a 5 -fluorouracil $(n=133)$ or capecitabine $(n=18)$. Most patients $(n=133)$ underwent a 5 -fluorouracil $500 \mathrm{mg} / \mathrm{m}^{2}$ intravenous (IV) bolus injection for 3 days during week 1 and 5 of CRT, and 18 patients received capecitabine $1,650 \mathrm{mg} / \mathrm{m}^{2}$ daily on days with radiotherapy.

Total mesorectal excision was performed 5-12 weeks (median: 8.1 weeks) after preoperative CRT. Postoperative chemotherapy was administered to 142 patients (94.0\%). The reasons for not undergoing post-operative chemotherapy were as follows: patient refusal in 2 patients, comorbidities or old age in 4 patients, wound problem in 1 patient, and transfer to other hospital in 2 patients. The regimens of postoperative chemotherapy 
Table 1 Patient and treatment characteristics

\begin{tabular}{|c|c|}
\hline Characteristics & Value (\%) \\
\hline Median age, years (range) & $56(27-78)$ \\
\hline \multicolumn{2}{|l|}{ Gender } \\
\hline Male & $106(70.2)$ \\
\hline Female & $45(29.8)$ \\
\hline \multicolumn{2}{|l|}{ ECOG } \\
\hline 0 & $40(26.5)$ \\
\hline 1 & $110(72.8)$ \\
\hline 2 & $1(0.7)$ \\
\hline \multicolumn{2}{|l|}{ Clinical T stage } \\
\hline $\mathrm{T} 1 / \mathrm{T} 2$ & $0(0.0) / 14(9.3)$ \\
\hline $\mathrm{T} 3 / \mathrm{T} 4$ & $126(83.5) / 11(7.2)$ \\
\hline \multicolumn{2}{|l|}{ Clinical N stage } \\
\hline$N(-)$ & $31(20.5)$ \\
\hline$N(+)$ & $120(79.5)$ \\
\hline \multicolumn{2}{|l|}{ Distance from anal verge $(\mathrm{cm})$} \\
\hline$\leq 5 \mathrm{~cm}$ & $120(79.5)$ \\
\hline$>5 \mathrm{~cm}$ & $31(20.5)$ \\
\hline \multicolumn{2}{|l|}{ Pretreatment CEA } \\
\hline Normal ( $\leq 5 \mathrm{ng} / \mathrm{ml})$ & $107(70.9)$ \\
\hline Elevated (> 5 ng/ml) & $44(29.1)$ \\
\hline Median radiation dose, Gy (range) & $50.4(50.4-55.8)$ \\
\hline \multicolumn{2}{|l|}{ Combined chemotherapy } \\
\hline 5-fluorouracil & $133(88.1)$ \\
\hline Capecitabine & $18(11.9)$ \\
\hline \multicolumn{2}{|l|}{ Type of surgery } \\
\hline Low anterior resection & $139(92.1)$ \\
\hline Abdominoperineal resection & $12(7.9)$ \\
\hline \multicolumn{2}{|l|}{ Pathology } \\
\hline Adenocarcinoma & $143(94.7)$ \\
\hline Mucinous carcinoma & $7(4.6)$ \\
\hline Signet ring cell carcinoma & $1(0.7)$ \\
\hline \multicolumn{2}{|l|}{ ypT stage } \\
\hline $\mathrm{Tis} / \mathrm{T1}$ & $3(2.0) / 10(6.6)$ \\
\hline $\mathrm{T} 2 / \mathrm{T} 3$ & $49(32.5) / 89(58.9)$ \\
\hline \multicolumn{2}{|l|}{ ypN stage } \\
\hline NO & $94(62.3)$ \\
\hline N1 & $47(31.1)$ \\
\hline N2 & $10(6.6)$ \\
\hline \multicolumn{2}{|l|}{ Lymphatic invasion } \\
\hline Yes & 19 (12.6) \\
\hline No & $132(87.4)$ \\
\hline \multicolumn{2}{|l|}{ Vascular invasion } \\
\hline Yes & $7(4.6)$ \\
\hline No & $144(95.4)$ \\
\hline
\end{tabular}

Table 1 Patient and treatment characteristics (Continued)

\begin{tabular}{lc}
\hline Perineural invasion & \\
Yes & $23(15.2)$ \\
No & $128(84.8)$ \\
\hline
\end{tabular}

Values in parentheses are percentages unless indicated otherwise. Gy, Gray; CEA, carcinoembryonic antigen.

were fluouracil-leucovorin $(n=111)$, capecitabine $(n=$ $21)$, or FOLFOX $(n=10)$. Fluouracil-leucovorin regimen was 6 cycles of 5 -fluorouracil $400 \mathrm{mg} / \mathrm{m}^{2}$ IV bolus and leucovorin $20 \mathrm{mg} / \mathrm{m}^{2}$ IV bolus for 5 days every 4 weeks. Capectabine was given $1250 \mathrm{mg} / \mathrm{m}^{2}$ twice daily without drug holiday for 2 weeks followed by one week rest repeated every 3 weeks upto 8 cycles for 6 months. FOLFOX regimen was either FOLFOX-4 or modified FOLFOX-6. Each cycle of FOLFOX-4 consisted of oxaliplatin $(85 \mathrm{mg} / \mathrm{m} 2)$ on day 1 and folinic acid $(200 \mathrm{mg} / \mathrm{m} 2)$ and a bolus of 5 -FU $(400 \mathrm{mg} / \mathrm{m} 2)$ followed by a $22-\mathrm{hr}$ infusion of 5-FU $(600 \mathrm{mg} / \mathrm{m} 2)$ on days 1 and 2 , which was repeated every 2 weeks. Modified FOLFOX-6 consisted of oxaliplatin $(85 \mathrm{mg} / \mathrm{m} 2)$, folinic acid $(400 \mathrm{mg} / \mathrm{m} 2)$ and a bolus of 5 -FU $(400 \mathrm{mg} / \mathrm{m} 2)$ followed by a $46-\mathrm{hr}$ infusion of $5-\mathrm{FU}(2400 \mathrm{mg} / \mathrm{m} 2)$ repeated every 2 weeks.

\section{Pathologic evaluation}

Surgical specimens were evaluated by pathologists to estimate and grade the pathologic responses of CRT. The pathologic responses were categorized into 4 tiers as reported previously [11]. No regression was defined as no evidence of radiation-related changes (fibrosis, necrosis, vascular change). Minimal regression was defined as dominant tumor mass with obvious radiation-related changes. Moderate regression was defined as dominant radiationrelated changes with residual tumor. Near total regression was defined as microscopic residual tumor in fibrotic tissue. This grading system evaluates tumor regression grade on the basis of proportion between radiation change and residual tumor burden similar to that of Dworak's system [12]. Thus, no regression, minimal regression, moderate regression, and near total regression correspond to grade $0,1,2$, and 3 of Dworak's system, respectively.

The CRM and DRM of the surgical specimens were inked and fixed in formalin. The resected specimens were sliced and measured by ruler. When the CRM taken from gross section is below $2 \mathrm{~mm}$, microscopic measurement was performed to evaluate the exact length in a tenth of a millimeter. Sufficient blocks of the primary tumor and lymph nodes related to CRM were taken. When the tumor, lymph node, vascular invasion, or tumor satellites were found close to the margin, microscopic measurement was repeated to validate the exact length of RM.

To evaluate the relationship between the effect of CRM and treatment response to preoperative CRT, 
patients were arbitrarily divided into two subgroups: good responders and poor responders. Good responder was defined as patients showing near total regression or down-staging of $\mathrm{T}$ stage, whereas poor responder was defined as patients showing none of two features.

\section{Statistical analysis}

Overall survival (OS) was defined as the time from the first date of treatment to the date of death from any cause, with survivors being censored at the time of last follow-up. Disease-free survival (DFS) was calculated as the interval from the first date of treatment to any recurrent disease detection or death, whichever occurred first. Locoregional control rate (LRC) was defined as the time from the first date of treatment to the date of locoregional relapse detected in pelvic cavity. Distant metastasisfree survival (DMFS) was calculated as the interval from the first date of treatment to distant metastasis detection or death, whichever occurred first. Patients who were alive and disease free at the time of last follow-up were censored.

Survival curves were generated by the Kaplan-Meier method, and a univariate survival comparison was performed using the log-rank test. Multivariate analyses were conducted using the Cox proportional hazards model backward stepwise selection procedure. Chi-square test was used for comparison of parameters between subgroups in good responders. P-value $<0.05$ was considered statistically significant. Maxstat, the maximally selected rank method in $\mathrm{R}$ 2.15.1 ( $\mathrm{R}$ Development Core Team, Vienna, Austria, http://www.R-project.org) was used to identify optimal cutting points for RM [13]. Cutting points for RM as studied for all studied endpoints including, OS, DFS, LCR, and DMFS. The maximally selected rank method analyzed RM as a continuous variable.

\section{Results}

\section{Treatment response and survival}

As for the pathologic response to preoperative CRT, near total regression was found in $16.5 \%$ and down-staging of $\mathrm{T}$ stage occurred in $40.4 \%$ patients. Down-staging from cT2 to ypTis was found in 1 patient $(0.7 \%)$, from cT3 to ypTis, ypT1 and ypT2 in 2 (1.3\%), 10 (6.6\%) and 37 patients $(24.5 \%)$, and from cT4 to ypT2, and ypT3 in 2 $(1.3 \%)$, and 9 patients $(6.0 \%)$, respectively.

The median follow-up time for surviving patients was 43.1 months. Five-year OS, DFS, LRC, and DMFS were $84.5 \%, 72.8 \%, 86.3 \%$, and $74.2 \%$, respectively (Figure 1 ).

\section{The optimal cutting point and prognostic impact of resection margin}

To determine which level of RM segregated patients with maximal difference of survival, a maximally selected rank method was adapted. This method found that

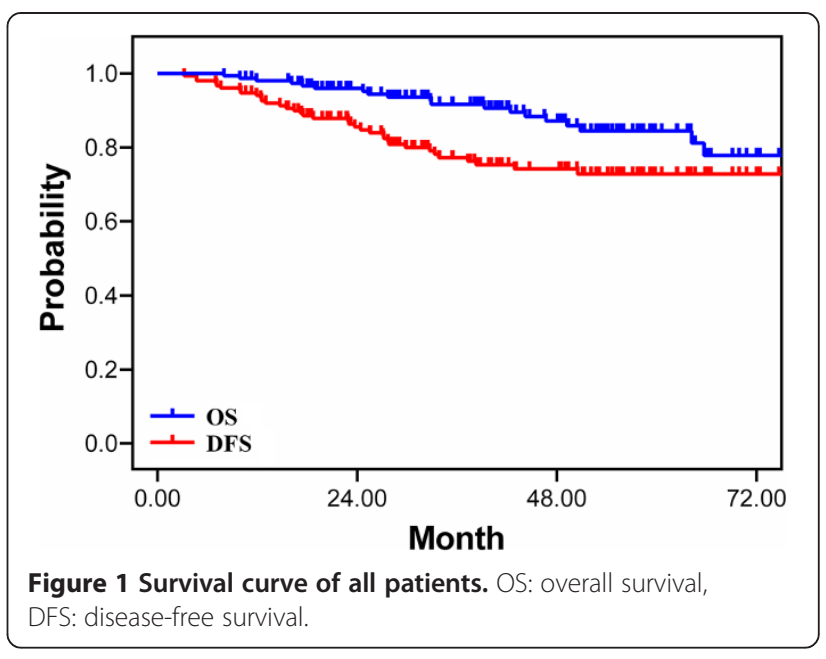

$1.5 \mathrm{~mm}$ of CRM and $7 \mathrm{~mm}$ of DRM was the optimal cutting point for all studied end-points including OS, DFS, LRC, and DMFS. After applying the criterion of positive margin as CRM $\leq 1.5 \mathrm{~mm}$ and $\mathrm{DRM} \leq 7 \mathrm{~mm}$, the number of patients with positive CRM and DRM were 32 and 80, respectively. In univariate analysis, CRM of $1.5 \mathrm{~mm}$ was found to be a significant prognostic factor for OS $(\mathrm{p}<.001)$, DFS $(\mathrm{p}<.001)$, LRC $(\mathrm{p}<.001)$ and DMFS $(\mathrm{p}<.001)$, whereas the DRM shorter than $7 \mathrm{~mm}$ was not a significant prognostic factor. The results of univariate analysis are shown in Table 2.

\section{Analysis of prognostic factors}

The univariate analysis of other prognostic factors is also shown in Table 2. Type of surgery, ypN, vascular, and perineural invasion were significant prognostic factors correlated with OS $(\mathrm{p}=<0.001,<.001,0.047$, and $<0.001$, respectively). Type of surgery, ypT, ypN, downstage, lymphatic, vascular, and perineural invasion were significant prognostic factors for DFS $(\mathrm{p}=<0.001,0.036$, $<0.001,<0.001,0.004,0.026$, and $<0.001$, respectively). Likewise, type of surgery, ypN, lymphatic, vascular, and peri-neural invasion also had significant prognostic effect on LRC and DMFS. In contrast, age, sex, performance score, clinical stage, CEA, distance of tumor from anal verge, pathologic type, and pathologic response lacked statistical significance on above mentioned various clinical end-points.

In the multivariate analysis, ypN and CRM of $1.5 \mathrm{~mm}$ were independent prognostic factors for prediction of OS, DFS, LRC, and DMFS. For DFS and DMFS, ypT and lymphatic invasion were statistically significant. In addition, perineural invasion was an independently significant prognostic factor for OS and LRC. In contrast to CRM, DRM of $7 \mathrm{~mm}$ was not significant in multivariate analysis as well as univariate analysis (Tables 2 and 3). 
Table 2 Results of univariate analysis

\begin{tabular}{|c|c|c|c|c|c|c|c|c|}
\hline & $5 y$ OS & pt & 5y DFS & $\mathrm{pt}$ & $5 y$ LRC & pt & 5y DMFS & $\mathrm{pt}$ \\
\hline \multicolumn{9}{|l|}{ Age (years) } \\
\hline$<60$ & 85.7 & .647 & 69.3 & .240 & 82.7 & .201 & 71.3 & .349 \\
\hline$\geq 60$ & 82.8 & & 80.4 & & 94.4 & & 80.3 & \\
\hline \multicolumn{9}{|l|}{ Gender } \\
\hline Male & 83.2 & .477 & 70.4 & .412 & 84.0 & .365 & 70.4 & .155 \\
\hline Female & 87.7 & & 79.2 & & 92.5 & & 84.1 & \\
\hline \multicolumn{9}{|l|}{ ECOG score } \\
\hline 0 & 87.5 & .561 & 80.0 & .388 & 94.9 & .218 & 80.0 & .506 \\
\hline $1-2$ & 83.5 & & 70.5 & & 83.4 & & 72.3 & \\
\hline \multicolumn{9}{|l|}{ Clinical T stage } \\
\hline $\mathrm{T} 2$ & 77.9 & .881 & 64.9 & .951 & 90.9 & .991 & 64.9 & .705 \\
\hline T3 & 84.9 & & 73.0 & & 85.8 & & 73.9 & \\
\hline T4 & 90.9 & & 81.8 & & 90.0 & & 90.9 & \\
\hline \multicolumn{9}{|l|}{ Clinical N stage } \\
\hline$N(-)$ & 90.5 & .208 & 81.0 & .229 & 94.7 & .115 & 81.0 & .301 \\
\hline$N(+)$ & 82.9 & & 70.5 & & 84.0 & & 72.2 & \\
\hline \multicolumn{9}{|c|}{ Distance from anal verge } \\
\hline$\leq 2 \mathrm{~cm}$ & 76.7 & .296 & 67.9 & .780 & 87.9 & .199 & 67.9 & .650 \\
\hline $2-5 \mathrm{~cm}$ & 83.9 & & 70.9 & & 76.7 & & 72.7 & \\
\hline$>5 \mathrm{~cm}$ & 92.2 & & 78.6 & & 92.6 & & 80.5 & \\
\hline \multicolumn{9}{|l|}{ Pretreatment CEA } \\
\hline$\leq 5 \mathrm{ng} / \mathrm{ml}$ & 86.8 & .617 & 77.6 & .162 & 91.0 & .081 & 78.5 & .213 \\
\hline$>5 \mathrm{ng} / \mathrm{ml}$ & 79.9 & & 62.8 & & 76.6 & & 65.3 & \\
\hline \multicolumn{9}{|l|}{ Type of surgery } \\
\hline LAR & 89.5 & $<.001$ & 75.6 & $<.001$ & 88.8 & $<.001$ & 77.1 & $<.001$ \\
\hline APR & 34.3 & & 40.0 & & 57.1 & & 40.0 & \\
\hline \multicolumn{9}{|c|}{ Patholgic response } \\
\hline None/Minimal & 83.7 & .228 & 62.8 & .096 & 78.2 & .073 & 64.9 & .125 \\
\hline Moderate & 80.1 & & 74.9 & & 89.2 & & 75.7 & \\
\hline Near total & 95.8 & & 86.2 & & 93.8 & & 86.4 & \\
\hline \multicolumn{9}{|l|}{ ypT stage } \\
\hline $\mathrm{Tis} / \mathrm{T} 1$ & 92.3 & .080 & 84.6 & .036 & 92.3 & .073 & 84.6 & .069 \\
\hline $\mathrm{T} 2$ & 93.3 & & 83.8 & & 95.6 & & 83.8 & \\
\hline T3 & 74.8 & & 63.1 & & 76.9 & & 65.4 & \\
\hline \multicolumn{9}{|l|}{ ypN stage } \\
\hline NO & 87.4 & $<.001$ & 85.5 & $<.001$ & 93.4 & $<.001$ & 86.7 & $<.001$ \\
\hline $\mathrm{N} 1$ & 85.9 & & 53.2 & & 76.3 & & 55.0 & \\
\hline N2 & 57.1 & & 36.0 & & 57.1 & & 36.0 & \\
\hline \multicolumn{9}{|l|}{ Downstage } \\
\hline Yes & 87.2 & .120 & 85.1 & $<.001$ & 84.3 & .213 & 86.5 & $<.001$ \\
\hline No & 80.6 & & 56.6 & & 87.9 & & 57.8 & \\
\hline
\end{tabular}


Table 2 Results of univariate analysis (Continued)

\begin{tabular}{|c|c|c|c|c|c|c|c|c|}
\hline \multicolumn{9}{|c|}{ Lymphatic invasion } \\
\hline Yes & 75.8 & .065 & 45.1 & .004 & 54.7 & $<.001$ & 45.1 & .002 \\
\hline No & 85.6 & & 76.9 & & 91.4 & & 78.5 & \\
\hline \multicolumn{9}{|c|}{ Vascular invasion } \\
\hline Yes & 71.4 & .047 & 38.1 & .026 & 57.1 & .002 & 38.1 & .017 \\
\hline No & 85.1 & & 74.7 & & 87.7 & & 76.2 & \\
\hline \multicolumn{9}{|c|}{ Perinerual invasion } \\
\hline Yes & 61.0 & $<.001$ & 32.1 & $<.001$ & 53.3 & $<.001$ & 32.1 & $<.001$ \\
\hline No & 88.6 & & 79.5 & & 91.4 & & 81.1 & \\
\hline \multicolumn{9}{|c|}{ Circumferential resection margin } \\
\hline$\leq 1.5 \mathrm{~mm}$ & 59.4 & $<.001$ & 48.4 & $<.001$ & 70.7 & $<.001$ & 48.4 & $<.001$ \\
\hline$>1.5 \mathrm{~mm}$ & 91.6 & & 79.3 & & 90.6 & & 81.1 & \\
\hline \multicolumn{9}{|c|}{ Distal resection margin } \\
\hline$\leq 7 \mathrm{~mm}$ & 92.1 & .010 & 73.0 & .525 & 88.3 & .116 & 74.1 & .559 \\
\hline$>7 \mathrm{~mm}$ & 75.5 & & 73.4 & & 84.3 & & 75.1 & \\
\hline
\end{tabular}

values are percentages of patients; +log rank test; 5y, 5-year; OS, overall survival; DFS, disease-free survival; LRC, locoregional control rates; DMFS, distant metastasis-free survival; ECOG, Eastern Cooperative Oncology Group; CEA, carcinoembryonic antigen; LAR, Low anterior resection; APR,Abdominoperineal resection.

\section{Different prognostic effect of CRM according to preoperative CRT response}

In the subgroup of good responders, CRM of $1.5 \mathrm{~mm}$ did not have any prognostic effect on all studied endpoints. In contrast, the poor responders demonstrated a significant difference in the clinical results according to the CRM status (Table 4 and Figure 2).

The distribution of significant factors in multivariate analysis were compared between patients with CRM $\leq 1.5 \mathrm{~mm}$ and CRM $>1.5 \mathrm{~mm}$ in good responders. The distribution of ypT, ypN, lymphatic invasion and perineural invasion, which were found to be significant factors in multivariate analysis, was not statistically different according to CRM status.

\section{Discussion}

The adequate cut off point of CRM is a subject of controversy. Since the initial proposal by Quirke et al., which favored distance of $1 \mathrm{~mm}$ over $0 \mathrm{~mm}$ as cut off point [8], several large prospective studies and guidelines have adopted criteria of $\leq 1 \mathrm{~mm}$ as CRM involvement $[5,14,15]$. On the contrary, Natagaal et al. reported that CRM of $\leq 2 \mathrm{~mm}$ was associated with high risk for local recurrence in the series of 656 rectal cancer patients without preoperative treatment and proposed CRM of $2 \mathrm{~mm}$ as the adequate limit [8]. However, this study was criticized for the treatment heterogeneity of patients included for analysis despite large sample size. Considering the regression effect of the conventionally fractionated preoperative CRT [3], the prognostic significance or adequate length in the setting of preoperative CRT may be different from patients undergoing up-front surgery or short-course radiotherapy. Current study assessed the effect and adequate length of RM in a homogenous cohort of rectal cancer patients who underwent conventionally fractionated preoperative CRT and total meosrectal excision. In addition, present study only included patients with narrow margin $(C R M \leq 0.5 \mathrm{~cm}$ or $\mathrm{DRM} \leq 1.0 \mathrm{~cm})$. In this way, present study accrued more homogenous cohort without abundant and unnecessary data, because the prognosis of patients with CRM $>0.5 \mathrm{~cm}$ or DRM $>1.0 \mathrm{~cm}$ is reported to be steadily good and not related to the effect of RM [8,16,17].

All studied end-points were segregated with maximal difference at CRM of $1.5 \mathrm{~mm}$ in current study. The adequate length of CRM has been controversial between $1 \mathrm{~mm}$ and $2 \mathrm{~mm}[5,14,15]$. In the similar patient group with long-course preoperative CRT, Trakarnsanga et al. recently reported that CRM of $1 \mathrm{~mm}$ is a cut-off value for local recurrence but $2 \mathrm{~mm}$ for distant recurrence [10]. While previous studies used simple comparison among arbitrarily divided groups, current study used continuous variable in micrometer dimension from microscopic measurements and analyzed RM with maximally selected rank statistics. As RM is a factually continuous variable and measurement in micrometer dimension is technically feasible, method used in current study could be considered as reasonable and statistically unbiased approach.

The second purpose of the present study was to assess the effect of treatment response on RM after preoperative CRT. In subgroup analysis based on the response to preoperative CRT, the impact of positive CRM was not significant in the good responders in contrast to the poor responders. As nearly all patients (94.0\%) received 
Table 3 Results of multivariate analysis

\begin{tabular}{|c|c|c|c|c|}
\hline & & $\mathrm{p}$ & RR & $95 \% \mathrm{Cl}$ \\
\hline \multirow[t]{6}{*}{$\overline{\text { OS }}$} & Type of surgery & NS & & \\
\hline & ypN & .016 & 2.24 & $1.16-4.34$ \\
\hline & Vascular invasion & NS & & \\
\hline & Perineural invasion & .024 & 2.99 & $1.15-7.77$ \\
\hline & CRM of $1.5 \mathrm{~mm}$ & .001 & 4.98 & $1.92-12.91$ \\
\hline & DRM of $7 \mathrm{~mm}$ & NS & & \\
\hline \multirow[t]{8}{*}{ DFS } & Type of surgery & NS & & \\
\hline & ypT & .005 & 2.65 & $1.35-5.19$ \\
\hline & ypN & $<.001$ & 2.96 & $1.74-5.02$ \\
\hline & Downstaging & NS & & \\
\hline & Lymphatic invasion & .011 & 2.97 & $1.29-6.85$ \\
\hline & Vascular invasion & NS & & \\
\hline & Perineural invasion & NS & & \\
\hline & CRM of $1.5 \mathrm{~mm}$ & .013 & 2.58 & $1.22-5.41$ \\
\hline \multirow[t]{6}{*}{ LRC } & Type of surgery & NS & & \\
\hline & ypN & .006 & 2.74 & $1.34-5.64$ \\
\hline & Lymphatic invasion & NS & & \\
\hline & Vascular invasion & NS & & \\
\hline & Perineural invasion & .004 & 4.65 & $1.64-13.19$ \\
\hline & CRM of $1.5 \mathrm{~mm}$ & .025 & 3.21 & $1.16-8.91$ \\
\hline \multirow[t]{8}{*}{ DMFS } & Type of surgery & NS & & \\
\hline & ypT & .007 & 2.55 & $1.29-5.06$ \\
\hline & ypN & $<.001$ & 2.55 & $1.29-5.06$ \\
\hline & Downstaging & NS & & \\
\hline & Lymphatic invasion & .007 & 3.24 & $1.38-7.59$ \\
\hline & Vascular invasion & NS & & \\
\hline & Perineural invasion & NS & & \\
\hline & CRM of $1.5 \mathrm{~mm}$ & .009 & 2.78 & $1.29-5.97$ \\
\hline
\end{tabular}

OS, overall survival; DFS, disease-free survival; LRC, locoregional control rates; DMFS, distant metastasis-free survival; CRM, circumferential resection margin; DRM, distal resection margin.

postoperative chemotherapy as the institutional treatment protocol, different impact of CRM could be assessed as difference in tumor biology and/or effect of postoperative chemotherapy. In the good responders, residual tumor cells resulting in positive CRM might consist of responsive or impending non-viable tumor cells. This responsive biology of residual tumor cells may have lost the prognostic significance of CRM after postoperative chemotherapy. In contrast, the residual tumor cells at CRM for poor responders might be resistant or viable, and this could mean aggressive biology related to deteriorated prognosis and resistance to adjuvant chemotherapy. This finding suggests why despite positive CRM, survival of subgroup of patients, namely good responders, is comparable to that of patients with negative CRM.
Table 4 Subgroup analysis according to preoperative treatment response

\begin{tabular}{|c|c|c|c|}
\hline & \multicolumn{2}{|c|}{ Good responders } & \multirow[b]{2}{*}{ pt } \\
\hline & $\mathrm{CRM}>1.5 \mathrm{~mm}$ & $\mathrm{CRM} \leq 1.5 \mathrm{~mm}$ & \\
\hline Number of patients & 63 & 10 & \\
\hline 5-year OS & 93.3 & 90.0 & .466 \\
\hline 5-year DFS & 87.6 & 90.0 & .948 \\
\hline 5-year LRC & 94.9 & 100.0 & .591 \\
\hline \multirow[t]{3}{*}{ 5-year DMFS } & 89.2 & 90.0 & .817 \\
\hline & \multicolumn{2}{|c|}{ Poor responders } & \\
\hline & CRM > $1.5 \mathrm{~mm}$ & $\mathrm{CRM} \leq 1.5 \mathrm{~mm}$ & $\mathrm{p} t$ \\
\hline Number of patients & 56 & 22 & \\
\hline 5-year OS & 87.4 & 48.4 & $<.001$ \\
\hline 5-year DFS & 76.0 & 30.5 & $<.001$ \\
\hline 5-year LRC & 85.7 & 58.0 & $<.001$ \\
\hline 5-year DMFS & 78.2 & 33.0 & $<.001$ \\
\hline
\end{tabular}

values are percentages unless indicated otherwise of patients; †log rank test. OS, overall survival; DFS, disease-free survival; LRC, locoregional control rates; DMFS, distant metastasis-free survival; CRM, circumferential resection margin.
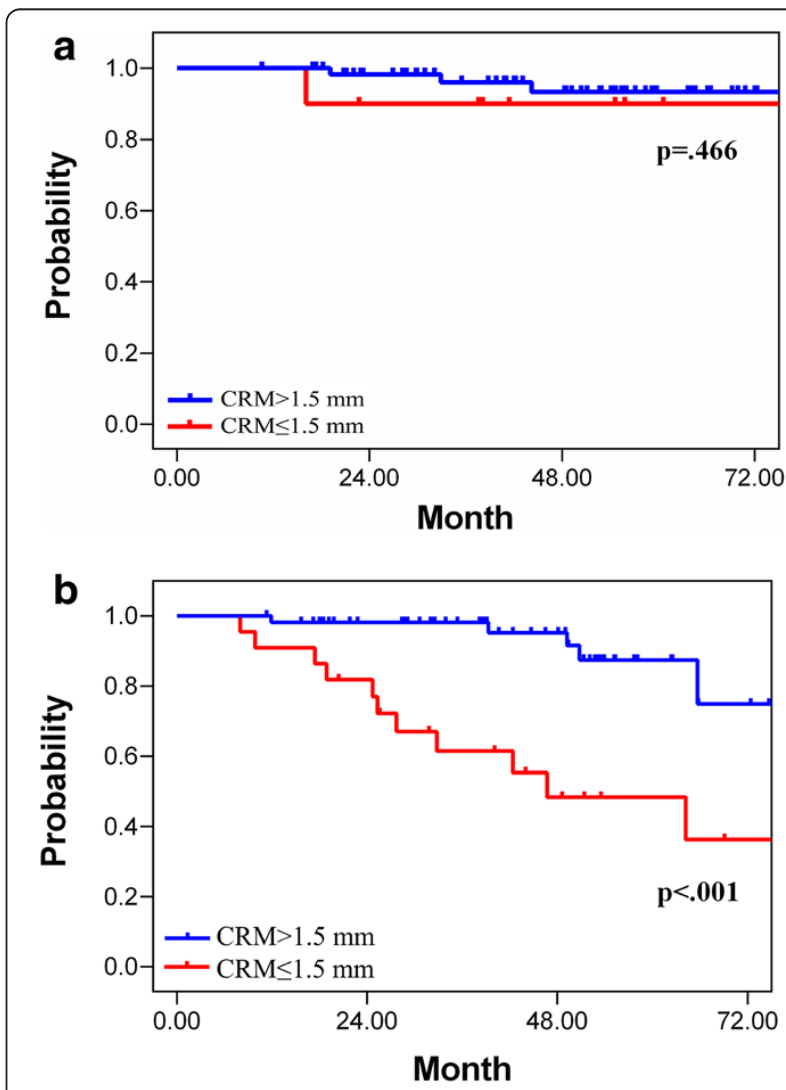

Figure 2 Overall survival curve according to CRM status in good responders (a) and poor responders (b). CRM: circumferential resection margin. 
While the treatment strategy compensating positive CRM has not been clearly established in previous studies $[4,5]$, results of current study may lead to hypothesis that postoperative treatment may be individualized based on treatment response. Local treatment approach such as postoperative radiotherapy or CRT has failed to compensate for positive CRM according to previous studies $[2,4]$. Systemic therapy may be required because positive CRM is related with high risk for distant metastasis as demonstrated in the current study as well as other studies $[6,7,9,10,14]$. EORTC 22921 showed that the tumor biology could be linked to the effect of chemotherapy [18]. In this trial, patients downstaged by preoperative CRT were more likely to benefit from adjuvant chemotherapy. Results from current study, where nearly all patients $(94.0 \%)$ received postoperative chemotherapy, also suggest that long-term survival may be expected for good responders, despite positive CRM. This may serve as a foundation for further studies to establish postoperative treatment strategy based on tumor biology for positive CRM.

Interestingly, DRM of $7 \mathrm{~mm}$, which showed the maximal survival difference, was not prognostic for all studied end-points in both univariate and multivariate analysis. Previous pathologic studies reported that subclinical distal bowel intramural spreads are found within $1 \mathrm{~cm}$ distally from visible tumor [16,19]. Accordingly, $1 \mathrm{~cm}$ DRM has been recommended [15]. However, in the systemic review of Bujko et al., length of DRM was not correlated with recurrence rates or survival. So, it was concluded that $<1 \mathrm{~cm}$ DRM did not jeopardize oncologic safety [17]. Particularly in the setting of preoperative treatment, other previous studies also proposed that $<1 \mathrm{~cm}$ could be accepted without compromising clinical outcomes $[20,21]$, and the result of present study in the setting of the conventionally fractionated preoperative CRT also supports this notion. Thus, narrow DRM defined as $<1 \mathrm{~cm}$ could be acceptable for the patients undergoing the conventionally fractionated preoperative CRT.

Present study is not free from limitations. First, although all patients were treated with similar protocol at single institution, not all patients underwent postoperative chemotherapy as described above. Secondly, although the distribution of subgroup was well balanced for significant prognostic factors, due to retrospective nature of the study design, some of possible statistical bias may have not been removed. Thirdly, present study lacked comparative group without adjuvant treatment to confirm the role of adjuvant chemotherapy for patients with positive CRM. Therefore, suggested influence of the treatment response on the impact of CRM could be a promising hypothesis for further studies with larger cohort, but this needs to be validated.

\section{Conclusions}

Close CRM, defined as $1.5 \mathrm{~mm}$, was a significant prognosticator, but the impact was different for treatment response to preoperative CRT. Postoperative treatment strategy may be individualized based on this finding. However, findings from this study need to be validated with larger cohort.

\section{Competing interests}

The authors declare that they have no competing interests.

\section{Authors' contributions}

EKC contributed to conception and design of the study, and revised the manuscript. JHL, KK and SWH contributed to analysis and interpretation of data, and drafted the manuscript. SJ, KJP, JP, GHK, SH, DO, SI, TK, and YB participated in data acquisition and literature research. All authors read and approved the final manuscript.

\section{Author details}

${ }^{1}$ Department of Radiation Oncology, Seoul National University College of Medicine, Seoul, Korea. ${ }^{2}$ Department of Surgery, Seoul National University College of Medicine, Seoul, Korea. ${ }^{3}$ Department of Pathology, Seoul National University College of Medicine, Seoul, Korea. ${ }^{4}$ Department of Internal Medicine, Seoul National University College of Medicine, Seoul, Korea. ${ }^{5}$ Institute of Radiation Medicine, Medical Research Center, Seoul National University, Seoul, Korea.

Received: 5 June 2013 Accepted: 5 November 2013

Published: 5 December 2013

\section{References}

1. Adam IJ, Mohamdee MO, Martin IG, Scott N, Finan PJ, Johnston D, Dixon MF, Quirke P: Role of circumferential margin involvement in the local recurrence of rectal cancer. Lancet 1994, 344:707-711.

2. Bernstein $T E$, Endreseth $B H$, Romundstad $P$, Wibe $A$ : What is a safe distal resection margin in rectal cancer patients treated by low anterior resection without preoperative radiotherapy? Colorectal Dis 2012, 14:e48-e55.

3. Bujko K, Nowacki MP, Nasierowska-Guttmejer A, Michalski W, Bebenek M, Kryj M: Long-term results of a randomized trial comparing preoperative short-course radiotherapy with preoperative conventionally fractionated chemoradiation for rectal cancer. Br J Surg 2006, 93:1215-1223.

4. Marijnen CA, Nagtegaal ID, Kapiteijn E, Kranenbarg EK, Noordijk EM, van Krieken JH, van de Velde CJ, Leer JW: Radiotherapy does not compensate for positive resection margins in rectal cancer patients: report of a multicenter randomized trial. Int J Radiat Oncol Biol Phys 2003, 55:1311-1320.

5. Sebag-Montefiore D, Stephens RJ, Steele R, Monson J, Grieve R, Khanna S, Quirke P, Couture J, de Metz C, Myint AS, Bessell E, Griffiths G, Thompson LC, Parmar M: Preoperative radiotherapy versus selective postoperative chemoradiotherapy in patients with rectal cancer (MRC CR07 and NCICCTG C016): a multicentre, randomised trial. Lancet 2009, 373:811-820.

6. Baik SH, Kim NK, Lee YC, Kim H, Lee KY, Sohn SK, Cho CH: Prognostic significance of circumferential resection margin following total mesorectal excision and adjuvant chemoradiotherapy in patients with rectal cancer. Ann Surg Oncol 2007, 14:462-469.

7. Glynne-Jones R, Mawdsley S, Novell JR: The clinical significance of the circumferential resection margin following preoperative pelvic chemoradiotherapy in rectal cancer: why we need a common language. Colorectal Dis 2006, 8:800-807.

8. Nagtegaal ID, Marijnen CA, Kranenbarg EK, van de Velde CJ, van Krieken JH: Circumferential margin involvement is still an important predictor of local recurrence in rectal carcinoma: not one millimeter but two millimeters is the limit. Am J Surg Pathol 2002, 26:350-357.

9. Nagtegaal ID, Quirke P: What is the role for the circumferential margin in the modern treatment of rectal cancer? J Clin Oncol 2008, 26:303-312.

10. Trakarnsanga A, Gonen M, Shia J, Goodman KA, Nash GM, Temple LK, Guillem JG, Paty PB, Garcia-Aguilar J, Weiser MR: What is the significance of 
the circumferential margin in locally advanced rectal cancer after neoadjuvant chemoradiotherapy? Ann Surg Oncol 2013, 20:1179-1184.

11. Chang HJ, Park CK, Kim WH, Kim YB, Kim YW, Kim HG, Bae HI, Song KS, Chang MS, Chang HK: A standardized pathology report for colorectal cancer. Korean J Pathol 2006, 40:193-203.

12. Dworak O, Keilholz L, Hoffmann A: Pathological features of rectal cancer after preoperative radiochemotherapy. Int I Colorectal Dis 1997, 12:19-23.

13. Hothorn T, Lausen B: On the exact distribution of maximally selected rank statistics. Comput Stat Data Anal 2003, 43:121-137.

14. van Gijn W, Marijnen CA, Nagtegaal ID, Kranenbarg EM, Putter H, Wiggers T, Rutten HJ, Pahlman L, Glimelius B, van de Velde CJ: Preoperative radiotherapy combined with total mesorectal excision for resectable rectal cancer: 12-year follow-up of the multicentre, randomised controlled TME trial. Lancet Oncol 2011, 12:575-582.

15. The NCCN guideline version 4.2013 for rectal cancer: http://www.nccn.org/ professionals/physician_gls/pdf/rectal.pdf.

16. Chmielik E, Bujko K, Nasierowska-Guttmejer A, Nowacki MP, Kepka L, Sopylo R, Wojnar A, Majewski P, Sygut J, Karmolinski A, Huzarski T, Wandzel P: Distal intramural spread of rectal cancer after preoperative radiotherapy: the results of a multicenter randomized clinical study. Int $J$ Radiat Oncol Biol Phys 2006, 65:182-188.

17. Bujko K, Rutkowski A, Chang GJ, Michalski W, Chmielik E, Kusnierz J: Is the $1-\mathrm{cm}$ rule of distal bowel resection margin in rectal cancer based on clinical evidence? A systematic review. Ann Surg Oncol 2012, 19:801-808.

18. Collette L, Bosset JF, den Dulk M, Nguyen F, Mineur L, Maingon P,

Radosevic-Jelic L, Piérart M, Calais G: Patients with curative resection of cT3-4 rectal cancer after preoperative radiotherapy or radiochemotherapy: does anybody benefit from adjuvant fluorouracil-based chemotherapy? A trial of the European Organisation for Research and Treatment of Cancer Radiation Oncology Group. J Clin Oncol 2007, 25:4379-86.

19. Mezhir JJ, Smith KD, Fichera A, Hart J, Posner MC, Hurst RD: Presence of distal intramural spread after preoperative combined-modality therapy for adenocarcinoma of the rectum: what is now the appropriate distal resection margin? Surgery 2005, 138:658-663. discussion 663-654.

20. Pricolo VE, Abodeely A, Resnick M: Distal margins in radical resections for rectal cancer after chemoradiation therapy: how short is long enough? Dig Surg 2010, 27:185-189.

21. Rutkowski A, Bujko K, Nowacki MP, Chmielik E, Nasierowska-Guttmejer A, Wojnar A: Distal bowel surgical margin shorter than $1 \mathrm{~cm}$ after preoperative radiation for rectal cancer: is it safe? Ann Surg Oncol 2008, 15:3124-3131.

doi:10.1186/1471-2407-13-576

Cite this article as: Lee et al:: The influence of the treatment response on the impact of resection margin status after preoperative chemoradiotherapy in locally advanced rectal cancer. BMC Cancer 2013 13:576

\section{Submit your next manuscript to BioMed Central and take full advantage of:}

- Convenient online submission

- Thorough peer review

- No space constraints or color figure charges

- Immediate publication on acceptance

- Inclusion in PubMed, CAS, Scopus and Google Scholar

- Research which is freely available for redistribution 